\title{
Of Special Interest
}

\section{Report On "The Penn State}

Resource Center: A Faculty Vision Becomes Reality"

JOHN E. BENDER

Department of Chemistry

The University of Michigan

Ann Arbor, MI 48109

jbender@chem.Isa.umich.edu

The Penn State

Resource Center is basically a

large room with

lots of chemistry

things and lots of students.
T $\mathrm{n}$ this workshop, Peter Jurs and Robert Minard presented a concise, easily applied formula for improving the overall quality of the learning experience at a large state school through simple reading into student psychology. Using the example of a local beer garden, known for its activity, noise, and boisterousness, a "chaotic" approach was described for designing a chemistry learning center attractive to students. The facility integrates all undergraduate laboratory

"The Penn State Resource Center: A Faculty Vision Becomes Reality" by Peter Jurs and Robert Minard was presented at the "Day 2 to 40" workshop symposium held May 10-11, 1997. The two-day event was held in the Willard $\mathrm{H}$. Dow Chemical Sciences laboratory building on the central campus of The University of Michigan in Ann Arbor, Michigan. Each of the articles that comprise this issue was written by one of the group of reporters whom I asked to attend each session to take field notes and then follow up with the session leader and participants afterwards.

-Brian P. Coppola, Proceedings Editor 
instrumentation and study areas into one room with an atmosphere that is oriented to the student culture. Workshop participants concur that such an approach begins to address the problem of students being too distracted by nonacademic activities on campus after class. The development of this program was reported to greatly improve the level of peer interaction, group learning, and create a more positive response by majors and nonmajors alike to chemistry at Penn State. The success of the learning center in bringing in students suggests that this approach is not limited to chemistry, but is perhaps applicable to other fields of experimental science. Other departments at Penn State are currently exploring this option.

\section{Chronology}

1. Peter Jurs began by presenting the nature of teaching chemistry at Penn State. It was emphasized that class sizes are large with one thousand a year entering organic chemistry and two thousand a year entering general chemistry. The large number of students also means a diverse class composition. Majors are a small proportion of these classes, but are very active in undergraduate research. It was reported that at least $80 \%$ of chemistry majors do undergraduate research, and $50 \%$ continue on to graduate school. The facilities for teaching chemistry are disjoint with main offices and research laboratories in one building and lecture halls grouped together with other departments in a separate building. All general and organic chemistry courses are taught in the large lecture halls, which are poorly maintained, and do not even contain periodic tables for student use.

2. Attempts to date by the chemistry department at improving teaching are summarized. Honors classes, a summer undergraduate-research focus, separate administrative offices for undergraduates, a class on chemistry professions and career opportunities, and the elimination of divisions with much more fluid "interest groups" were all discussed. These changes, which are described as beneficial, still have not gone far enough to improve the chemistry situation at Penn State. It was reported that the chemistry department had steadily lost majors to the life sciences. The lack of general appeal for chemistry early on in the curriculum was cited as a cause. 
3. Robert Minard took over the workshop and passed out a copy of an open letter to the Penn State faculty from the Senate Officers. It details the crisis in student academic performance over time, noting particularly the role that out-of-classroom social activities play in impeding progress. No suggestions were made in the letter concerning how to approach this problem. The Penn State Resource Center was presented as an answer to this challenge by Jurs and Minard. The point was made that this project was intended to be modest in scope from the outset. The resistance to changes in teaching, frequently encountered at academic institutions, was to be avoided. The slogan "evolution, not revolution" was coined by the workshop leaders to capture the feeling of the proposal. The program must involve small, incremental changes to be successful in the long term.

4. The construction, layout, and uses of the Penn State Resource Center were explained by Minard. A comparison was made with a local beer garden, to explain the approach to student psychology used: students like "chaos." The resource center is a large, essentially open space, containing study tables, laboratory instrumentation, and a computer cluster. The center is shared by undergraduates, and even graduate students from all classes. The concentration of instrumentation and computers requires students to use the center frequently, though the scheduling of such use is kept as flexible as possible to accommodate students. Music, played at a tolerable level, is used as an additional psychological device to make to center more student-friendly.

5. Secondary aspects of the program, such as undergraduate poster sessions and the reorganization of various chemical instruments were also explained by Minard.

6. Rich Lawton initiated a dialogue comparing the Penn State Resource Center with the University of Michigan chemistry building's Atrium. It was related that the Atrium, although incorporated into the design of the building by accident, now serves as a gathering place for students in much the same way as the Penn State Resource Center. The Atrium has the advantage of a central location within the main chemistry building and has a learning center adjacent to it. Students congregate there at all times of the day and frequently use it as an impromptu study area. 
7. Participants discussed how to introduce library skills into the curriculum. Jurs stated that Penn State has a formal class on library skills, whereas Lawton informed the group that the $\mathrm{U}$ of $\mathrm{M}$ induces students to use the literature by requiring them to obtain laboratory data from the original references. All workshop participants agreed that literature training is critical, but did not discuss further how to best approach this in the curriculum.

8. Jeff Kovac commented on the poor state of affairs at a main Administrator's office in dealing with how students spend their out-of-class time (less relevant digression on the nature of football games at various universities).

9. Workshop leaders discussed in tandem how to get resources for creating a Resource Center. They attempted to emphasize that questions of space and faculty time as well as simply getting the university's attention are just as critical, if not more so, than financial support. It was implied that big and ambitious programs requiring large grants of money may have their advantages, but changing a teaching curriculum also heavily involves faculty participation and support. Addressing the needs of undergraduate education at large research universities was still felt to be a priority on paper only.

\section{Report}

Many students pick a small college learning environment. The quality of education at big research universities has been adequately reinforced over many years through simple word-of-mouth: "You are just a number." "The professor only cares about his research." "My TA doesn't speak English." etc. In the competitive atmosphere of American higher education, the university is as much a business as a place of learning, and it seems that as more money becomes involved the more these two areas become entangled. Money, of course, is the least of the worries when a large and stifling bureaucracy gets superimposed upon it. How does one approach the path of improvement in the face of such daunting challenges?

Peter Jurs asked workshop participants to consider a school with approximately 30,000 students. From the chemistry department's perspective, they see 2,000 students per year registering for general (first-year) chemistry and nearly 1,000 students per year registering for organic (second-year) chemistry. The vast majority of these students are 
nonmajors. Considerable flexibility is required for meeting the needs of such a diverse student body. The existing facilities for the chemistry department are aging with, of course, no serious plans for upgrades in the near future. The shared lecture halls are in a separate building, and no special allowances are made for the specific needs of chemistry, not even periodic tables. Chemistry has for some time been steadily loosing enrollment in favor of the life sciences.

Some changes were made by the chemistry department to partially address these issues. An "honors" chemistry program does not exist, but a wide selection of classes is offered to meet various student needs and interests, including a special class (Chem 16), which surveys professional chemistry and job opportunities for chemists. Considerable effort is made to interest undergraduates in research, beginning with a special seminar series by faculty for recruiting, and then keeping students in the program with various scientific events and a strong summer research focus. Upwards of $80 \%$ of chemistry majors engage in research and a full $50 \%$ of those who graduate go on to some kind of professional school. Separate offices are maintained for undergraduates to keep them from getting lost in the ocean of greater administration.

The formula related by Jurs and Minard from Penn State University's department of chemistry "Gang of Six", aims to approach every aspect of the solution realistically: no big money, no big grant proposals, and especially no big changes. "Evolution, not revolution" was the theme emphasized by the workshop leaders. In "An Open Letter to Penn State Faculty From The Senate Officers," an argument is developed that attempts to show how administrative neglect of the student body's free time has become highly detrimental to the educational process. Whether or not it is the faculty's business to interfere in the free time of students, a large part of the learning process certainly occurs outside of the classroom/laboratory. Important points were also made about the examples that faculty members set with their own professional and personal conduct. Workshop participants voiced wholehearted agreement, especially those with experience at large state schools.

The Penn State Resource Center is basically a large room with lots of chemistry things and lots of students. It could be imagined as a boisterous, chaotic place, and this is intentionally so. A simple psychological argument was followed in its design: given a choice in ways to spend their free time or even their schedules, students choose chaos. One could attempt to motivate students in various ways to use their out-of-class time 
academically. The extremes of "sink or swim" to "touchy-feelly" psychology, as described by Jurs, were not the kind of approaches the Gang of Six had in mind. Observing the chaotic nature of a local beer garden and how much time students were motivated to spend there, a similar approach was used to create an all-hours learning center, independent of classroom rigors.

Professor Richard Lawton initiated a discussion of the similarities and differences of the "Atrium" at his own University of Michigan to the Penn State Resource Center. Unlike the PSRC, the "Atrium" occurred accidentally in the course of designing the new wing of the $\mathrm{U}$ of $\mathrm{M}$ chemistry building. To handle the large volumes of recycled air that would be created as a result of the ventilation system, an air buffer was needed and this resulted in a four-story enclosed space right in the middle of the new wing. Savant personnel recognized the advantages of this unexpected design quirk and adapted the space to create a kind of indoor park. My personal experience with the "Atrium" has borne out its success as a place for students to congregate in an informal atmosphere and its wide applicability to general social functions. Unlike the PSRC then, it was not a premeditated thing, though it serves somewhat the same function.

The PSRC has some interesting advantages over the "Atrium," however. Much of the undergraduate chemistry instrumentation including instrumentation that is also useful to graduate students occupies space within the PSRC. The rooms for instrumentation and study are separate, but not disjoint. Teaching assistants and faculty are frequently on-hand to help with questions of instrumentation use, but the room is always filled with student learners and much peer instruction occurs. Simple interior design devices, such as extensive but uncoordinated coloration and unmatched tables, are used to make the room appear "used" and avoid a sterile or flashy effect. Music is always played at a tolerable and comfortable level. Such devices are intended to get students into the center, use it, and feel comfortable about being there. Because the laboratory instrumentation room serves all chemistry classes, many students become veterans of the learning center and hang out just to be with other students. The PSRC has only existed for a few years now, but it has already become an active forum for student activity.

The PSRC does not have extensive library learning facilities, but this is because library science skills are taught in a separate course by the PSU chemistry department. Lawton commented that such things are taught indirectly at the $\mathrm{U}$ of $\mathrm{M}$ by forcing students in 
laboratory classes to go to the original literature to get preparations for and data on their target compounds. Jeff Kovac suggested incremental introduction of library skills; however, no plan was conceived for it. The workshop participants did not reach a consensus as to which method was preferred.

Inception of the PSRC required an apparent minimum of resources, but this is deceiving. The amount of monetary resources required was small, but real problems were encountered elsewhere. A large enough space was not immediately available; this problem was further exacerbated by the disjoint nature of the chemistry offices, classrooms, and laboratories (all not in the same building). A separate space was finally acquired, although not before much wrangling with the administration occurred. Without sufficient funds to hire outside people to put together and actually run the center, faculty time was required, perhaps the scarcest of all resources. As Jurs puts it, "Where can I write a grant to get four more hours each day?" The seriousness with which faculty and staff take undergraduate education becomes pointedly obvious at this stage. Recognition of the PSRC has received the highest compliment possible, through imitative efforts in other departments. Direct acknowledgment however remains elusive and disheartening.

\section{Reflection}

This workshop was essentially a simple lecture, held for a small audience. The presentation of ideas seemed effective, and what little interaction was achieved with the workshop participants indicated that support for the ideas presented was strong. Jurs and Minard did not appear to structure their presentation to initiate participation from other workshop attendees. What little discussion was spontaneously initiated did not generate significant new ideas in the context of undergraduate education.

\section{Workshop Participants}

Peter Jurs (Leader; pcj@psu.edu), Robert Minard (Leader; rminard@psu.edu), John Bender (Reporter; jbender@U.Chem.LSA.UMich.edu), Robert Blake (rblake@mail. smu.edu), Michelle Julet (mrjulet@whfreeman.com), Jeff Kovac (jkovac@utk.edu), Richard Lawton (richy@umich.edu), Carl Wamser (wamserc@pdx.edu), Todd Woerner (woerner@chem.duke.edu), B. P. J. Coll. Sci. Teach. 1996, 25, 390. 